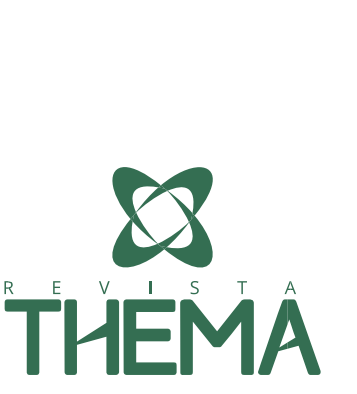

\title{
Relato de caso sobre o aprendizado em desenvolvimento de sistemas baseado no Framework Lavarel
}

\section{Case report on learning in systems development based on the Framework Lavarel}

Aline Silva De Bona ${ }^{1}$; Bruno Chaves Alvez Fernandes ${ }^{2}$; Marcelo Barbosa Magalhães ${ }^{3}$

\begin{abstract}
RESUMO
O trabalho pretende compartilhar a vivência do desenvolvimento de um sistema com a finalidade de realizar as inscrições de um evento de ensino - Semana Acadêmica Integrada no IFRS - Campus Osório, e gerar as listas de presença para cada atividade da programação. Tal foi realizado por quatro estudantes do curso superior Tecnologia em Análise e Desenvolvimento de Sistemas e baseado no Framework Laravel. O objetivo do relato de caso, alicerçado à experiência do evento, é de refletir sobre a aprendizagem de como se desenvolveu a construção e o quão complexa é a relação de quem solicita a criação de um sistema, o usuário, e o desenvolvedor, pois existem imprevistos, erros e prazos a serem cumpridos, além da escolha da ferramenta para a criação. A base teórica é a compreensão construtivista segundo a Teoria de Piaget do processo de aprendizagem desenvolvido por esses estudantes para a construção do sistema. Aponta-se um resultado do trabalho, além do sistema desenvolvido, as reflexões da comissão organizadora do quanto antes é preciso organizar as etapas de desenvolvimento de um sistema para que se minimizem os erros. A vivência dos estudantes formandos sobre como seria uma relação com o cliente também é apresentada.
\end{abstract}

Palavras-chave: Processo de Aprendizagem; Desenvolvimento de Sistema; Vivência da Teoria.

\begin{abstract}
The work intends to share the experience of the development of a system for the purpose of enrolling a teaching event - Academic Week Integrated in the IFRS - Campus Osório, and generate attendance lists for each activity programmed. This was carried out by four high school students - Technology in Analysis and Systems Development - and based on the Framework Lavarel The purpose of the case report, based on the experience of the event, is to reflect on the learning of how the construction was developed and how complex is the relationship among whoever requests the creation of a system, the user, and the developer, as there are unforeseen, errors and deadlines to be fulfilled, in addition to the choice of the tool for the creation. The theoretical basis is the constructivist understanding according to Piaget's Theory of the learning process developed by these students for the construction of the system. The paper presents result of the work, the system developed, and the reflections of the organizing committee on the sooner the stages of development of a system need to be organized to minimize the errors. The experience of the students graduating on how the relationship with the client would be like has also been reported.
\end{abstract}

Keywords: Learning Process; System development; Framework Laravel

1;2;3 IFRS - Instituto Federal de Educação, Ciência e Tecnologia do Rio Grande do Sul, Osório/RS - Brasil. 


\section{INTRODUÇÃO}

Atualmente os eventos, independente da finalidade, são, em geral, organizados por meio de algum sistema em rede, que tem a ele um banco de dados articulado para que os usuários possam, além de compartilhar informações, e fazer a inscrição, também guardar dados que podem ser usados posteriormente, como exemplo, para gerar uma lista de inscritos ou uma lista de e-mails para compartilhar algum lembrete do evento, e outros.

Cada vez mais se necessita do conhecimento das pessoas que atuam na área de desenvolvimento de sistemas. Exige-se que essas pessoas tenham a sensibilidade de compreender o que o usuário/cliente está solicitando para assim ter condições de fazer um estudo de como desenvolver o solicitado, tanto no que se refere à escolha de ferramentas e ao suporte para manutenção, como à usabilidade para manuseio do sistema.

Nos cursos de ensino superior, e particularmente os cursos de tecnólogos cuja duração é de apenas três anos, nas áreas que contemplam as tecnologias digitais em rede ou não, é muito comum, segundo Lévy (1994) e Morin (1999), que os estudantes não vivenciem experiências de fato que lhes permitam aplicar a teoria que aprenderam com clientes. Essas experiências, muitas vezes, limitam-se a simulações solicitadas em sala de aula pelos professores para fins didáticos.

Pensando em situações que relacionassem a teoria e prática, bem como a integração dos estudantes de três dos quatro cursos superiores noturnos oferecidos pelos IFRS - Campus Osório, e a possibilidade de estudar temas atuais e complementares que nem sempre conseguem ser previstos nas ementas tanto pelo fator tempo como pela atualidade, organizou-se o projeto de ensino denominado Semana Acadêmica Integrada ${ }^{4}$, primeiramente entre os professores, e, depois, com os estudantes voluntários. Os cursos superiores envolvidos foram: o Tecnólogo em Análise de Desenvolvimento de Sistemas (ADS), o Tecnólogo em Processos Gerenciais (TPG) e a Licenciatura em Matemática. Em dezembro de 2015, esse projeto iniciou-se com um professor de cada curso e o convite foi realizado via e-mail e pessoalmente para os estudantes dos cursos que tivessem interesse em participar na organização. O curso de Matemática que teve seu primeiro ingresso em 2016-1 participou a partir de fevereiro de 2016.

A comissão organizadora desse evento foi composta então por três estudantes de cada curso tecnólogo, mais dois estudantes da Matemática, os três professores mencionados anteriormente, e uma tecnóloga do campus. O projeto teve início em dezembro de 2015 e findou-se em 30 de maio de 2016. O evento ocorreu nos dias 5, 6 e 7 de maio de 2016, nos três turnos, exceto no sábado com atividades apenas de manhã e à tarde. A programação foi construída com três atividades em paralelo durante o dia, para que cada estudante pudesse escolher as que desejava participar. Tais atividades incluíam palestras, relatos de experiência, minicursos, apresentações e atividades culturais. À noite, as palestras eram centralizadas em temas comuns a qualquer curso superior, como, por exemplo, Inovação.

Entende-se por semana acadêmica um evento de grande conquista histórica dos estudantes por liberdade de saber e de compartilhamentos de ideias no espaço da instituição de ensino superior. Esse evento pode ser organizado exclusivamente por eles ou em parceria com professores e outros

\footnotetext{
${ }^{4}$ https://inf.osorio.ifrs.edu.br/smadi/informacao.php
} 
interessados que atuem na instituição. Ainda, a semana tem como finalidade geral a socialização dos estudantes e a possibilidade de vivências as quais, talvez, não sejam possíveis em sala de aula, como, por exemplo, um show de bandas com jantar de confraternização. Caracteriza-se, assim um espaço em que, como afirma Freire (1996), podem ocorrer trocas e diálogos que são importantes para a identificação com o curso e com a possibilidade de articulações com outras áreas do conhecimento. Isso pode ser percebido nessa semana que promove a integração de cursos das áreas das ciências exatas e das ciências sociais - administração, informática e matemática. Nessa semana acadêmica tinha-se duas áreas das exatas e uma das ciências sociais, no entanto se analisarmos que a matemática é a ciência do curso de licenciatura em matemática percebe-se que ainda existe a área da educação, que é das humanas, logo é uma oportunidade única participar desse evento porque em sala de aula é difícil ocorrer tamanha integração e/ou interdisciplinariedade.

Diante desse cenário, a semana acadêmica integrada foi muito bem recebida por todos os estudantes dos cursos e também da direção, possibilitando muito trabalho e realização de atividades, com a organização de grupos e equipes. Destinou-se ao grupo de estudantes do ADS participando da comissão organizadora a tarefa de fazer um sistema para as inscrições, para o qual um dos docentes, a coordenadora do projeto, havia pensado, inicialmente, em usar uma planilha de compartilhamento como o Google Docs ${ }^{\circledR}$. No entanto, uma aluna sugeriu o uso do Framework Laravel, pois já havia trabalhado com ele em outras disciplinas do curso. Assim, com a concordância de todos, foi iniciado o desenvolvimento do sistema. No início, havia mais dois colegas para ajudar, os quais por motivos de trabalho não puderam mais participar. Surgiu, então, a necessidade de que mais três colegas do ADS ajudassem a conseguir construir o sistema, sendo um deles também formando como ela e os outros dois, apesar de serem estudantes iniciantes, já haviam concluído o curso de técnicos em informática pela mesma instituição de ensino.

Neste artigo objetiva-se compartilhar e refletir apenas sobre uma das muitas atividades da comissão organizadora da semana acadêmica que é o aprendizado no decorrer do desenvolvimento do sistema, que teve início iniciou em final de fevereiro de 2016-e foi colocado em uso devido à necessidade de prazos, em meados de abril de 2016. Esse período representou dois meses de muito trabalho.

Não se pretende apresentar no artigo nem a construção nem o desenvolvimento técnico da programação do sistema. Por esse motivo, optou-se por citar a ferramenta usada Lavarel. Também não foram incluídas referências da área da informática tendo em vista que o foco estava em destacar a necessidade dos estudantes do ADS de "viverem situações reais" do que o mercado pode demandar deles, tendo com isso referências da área da educação. Com isso em vista, o artigo está organizado, inicialmente, pela introdução, depois estudo teórico, metodologia e ação, análise de dados, resultados e considerações finais e encerra com as referências. 


\section{O PROCESSO DE APRENDIZAGEM DO DESENVOLVIMENTO DE UM SISTEMA POR ESTUDANTES DO ADS PARA A SEMANA ACADÊMICA INTEGRADA DO IFRS - CAMPUS OSÓRIO}

Primeiramente, vale explicar os motivos pelos quais uma estudante do ADS, denominada A, dentre os quatro envolvidos do curso, sugeriu usar a ferramenta Framework Laravel ${ }^{5}$, e os demais colegas aceitaram a ideia. Com vistas à elaboração e registro deste artigo, enviou-se mensagem por email para a estudante perguntando-Ihe a respeito de seus motivos. A transcrição literal ${ }^{6}$ de sua resposta em maio de 2016 informa que:

Aceitei iniciar o projeto da semana acadêmica em php porque já programava em Python para a web, o que inclusive é lindo, e desejava aprender php, eu tinha um grande preconceito, pois o php é uma linguagem não tipada, de fácil utilização e que suporta praticamente tudo, isso faz com que muitas pessoas que estão iniciando na programação desenvolvam em php, com o tempo a aplicação cresce, sem um padrão de projeto, sem documentação e simplesmente vai pro lixo, pois se torna impossível de dar manutenção. Como não queria gerar uma aplicação inutilizável e queria aprender optei por utilizar um framework que me desse uma estrutura inicial, que abstrai-se problemas de rotas amigáveis, conexões com banco de dados e que utilizasse uma linguagem de template no html, acho intrusivo escrever php no html e acho interessante poder fazer herança no html e macros, o que de fato o Laravel propicia muito bem. Além disso posso recompilar o framework para adicionar features que ele não disponibilize ou que ninguém tenha feito biblioteca, isso me permite personalizar mesmo utilizando um framework. Com o decorrer do tempo outras vantagens foram percebidas, inicialmente eu estava desenvolvendo sozinha, mas precisamos desenvolver em grupo e o fato de usar um framework, com uma estrutura limpa e ampla documentação ajudou o grupo a entender a estrutura do projeto mais rapidamente.

Desculpe, esqueci de citar o uso do Mysql, levei em consideração ser uma aplicação de pequeno porte, com pouca carga no banco de dados e ser um banco de dados com o qual já estava desenvolvendo outros projetos, além de estar familiarizada com o console. Todos esses aspectos me persuadiram fortemente. Hoje talvez desenvolvesse com o PostgreSQL, mesmo sendo um banco de dados utilizado para grandes fluxos. (Estudante A, por e-mail).

Ao observar as respostas da estudante percebe-se que ela tem diferentes argumentos para justificar a escolha, desde aspectos técnicos, específicos da área da informática, até os referentes ao seu processo de aprendizagem, ou seja, que mobilizariam sua curiosidade em aprender tal ferramenta.

Percebe-se que uma parte do trabalho foi realizada individual e isoladamente pelos estudantes e a outra parte foi construída em grupo. A compreensão do que cada um estava fazendo sem que houvesse necessidade de conversarem pessoalmente ou online decorre da "ampla documentação" que a ferramenta proporciona. Isso pode ser visto sob a ótica de Piaget (1973), para quem o processo de aprendizagem inicia por colaboração, ou seja, todos com um objetivo comum e cada um fazendo sua parte, depois conforme as atividades vão tornando-se densas e complexas para desenvolver do projeto ocorrem ações em que os estudantes precisam realizar juntos, e surge a necessidade de

\footnotetext{
${ }^{5}$ Destaca-se que o conhecimento técnico da área da informática apresentado neste artigo é dos estudantes, desde as escolhas de como fazer, e da linguagem até assumir os erros e dificuldades, pelo fato de que é uma vivência de uma situação real proposta aos estudantes do ADS de como seria desenvolver um produto para usuários não da área da informática.

${ }^{6}$ Segmentos de emails enviados pelos participantes ou de suas falas são apresentados em itálico com o intuito de diferenciar de citações teóricas textuais. Também são apresentados sem eventuais correções ortográficas ou de concordância.
} 
interagirem por cooperação, isto é, todos fazerem juntos. Esse "fazer juntos" no caso do desenvolvimento do sistema, não requer necessariamente que estejam online em tempo real, pois cada um além de corresponder com a ideia dos demais, complementa a solução que vem sendo desenvolvida. E em alguns momentos age por reciprocidade, se necessário, que é alterar alguma estrutura se visualizar uma solução mais rápida por exemplo.

Na área da Informática na Educação, Bona (2012) afirma que cada vez mais se faz necessário trabalhar, construir e desenvolver ações de forma cooperativa, pois são muitos olhares sobre o mesmo projeto. Portanto, a possibilidade de ele rapidamente ficar mais diversificado, é maior do que se desenvolvido sozinho. Isso encontra respaldo em Piaget (1973), pois o autor destaca que fazer junto é aprender muitas formas diferentes das formas individuais de resolver, e/ou maneiras de explicar o quê e como se resolver. Assim, segundo afirma o autor, ocorre um movimento espiral de construção conceitual paralelamente a esse processo, indo da prática à teoria e vice-versa, sendo um elemento de reflexão e crescimento fundamental para os estudantes em seu processo de formação.

A questão da "familiaridade" destacada pela estudante é importante, porque valoriza seus saberes anteriores e reconhece que eles podem ajudar e avaliar o desenvolvimento do sistema, sendo, inclusive, tal fato comentado por outros estudantes dentre o grupo dos quatro estudantes. Segundo Freire (1996), a consciência dos saberes que cada um tem é um primeiro passo para o processo de aprendizagem ser interessante. Acrescenta-se que isso pode ser mobilizador quando integrado com outros colegas, conforme Piaget (1973).

A linguagem técnica usada pelos quatro estudantes que desenvolveram o sistema é muito interessante como pode ser percebido no e-mail transcrito acima e ainda quando lhes foi perguntado se possuíam fundamentação teórica para apoiar o que estavam dizendo. Isso resultou no envio de material por parte de dois dos quatro estudantes à professora, do qual se selecionou o trecho de email transcrito a seguir (enviado pelo estudante B, no final do mês de maio de 2016):

Olha só, alguns materiais ótimos para a senhora entender o que a gente tá falando e explicando da escolha da ferramenta:

Este é um perguntar e respostas:

http://www.bitabit.eng.br/2014/03/06/laravel-o-framework-php-que-me-fez-voltara-gostar-de-programar/

Esse ele explica os motivos técnicos na língua da gente de sala de aula:

https://alphabraga.wordpress.com/2014/02/24/deixa-eu-te-falar-porque-o-laravel-emelhor-que-o-codeigniter/

Esse material introdutório:

http://www.devmedia.com.br/introducao-ao-framework-php-laravel/33173

Entrevista de um bom desenvolvedor:

http://www.laravel.com.br/por-que-laravel-uma-entrevista-exclusiva-com-vedovelli/" (Email do estudante B).

Observando o texto do e-mail verifica-se a familiaridade do estudante com a linguagem, e sua preocupação em explicar para a professora de matemática, que é coordenadora da semana acadêmica, os motivos da escolha da ferramenta para desenvolver o sistema. Esse fato é muito importante para o desenvolvimento profissional futuro dos estudantes. (FREIRE, 1996), pelo simples fato de que se faz necessário explicar o quê e o porquê fizemos algo quando se tratam de relações de trabalho com mais de uma pessoa, mesmo que ela seja cliente e fornecedor. 
A atitude dos estudantes em compartilhar links com a professora e tentar compartilhar materiais e explicar em suas próprias palavras para facilitar a compreensão é também uma evidência de aprendizagem colaborativa com a professora, e um fato de responsabilização do seu processo de aprendizagem no ensino superior.

Ainda cabe destacar que existem muitas orientações como, por exemplo, os parâmetros curriculares nacionais para a escola básica e outros documentos legais destinados a incrementar a Informática na Educação desde a Escola Básica até o Ensino Superior. Todas têm como finalidade geral promover o desenvolvimento tecnológico e científico dos estudantes articulados ao espaço e contexto social que se vive hoje norteado de tecnologias, conforme Morin (1999). Cita-se o Programa Nacional de Informática Educativa (Proninfe), que foi desenvolvido em 1989, com a Portaria Ministerial n. 549/89 (BRASIL, 1994), que tinha por finalidade: promover e desenvolver a informática educativa no Brasil, por meio de projetos e atividades, articulados e convergentes, apoiados em fundamentação pedagógica sólida e atualizada, de modo a assegurar a unidade política, técnica e científica imprescindível ao êxito dos esforços e investimentos envolvidos.

Tal programa estava sustentado em referências constitucionais (título VIII, capítulos III e IV da atual Constituição brasileira) relacionadas às áreas de educação, ciência e tecnologia, e visando a apoiar o desenvolvimento e a utilização da informática nos ensinos de primeiro, segundo e terceiro graus e na educação especial, e outras. E esse é citado no artigo pelo fato de que tal programa incentivava ações como esta que relatamos neste artigo da semana acadêmica. Isso está relacionado à importância de criar momentos dentro da instituição de ensino nos quais o estudante tivesse a oportunidade de desenvolver/criar/fazer alguma ação em que seu conhecimento teórico fosse testado (colocado em prática) e que na prática ocorressem novas reflexões e necessidade de estudos surgissem, como foi o caso desse evento de ensino relatado.

Vale lembrar o que Papert (1994) destaca sobre a necessidade de que a informática, seja no nível escolar que for, tenha significado para o estudante. Assim, projetos, nos quais os estudantes podem criar e escolher o que e como vão desenvolver podem ser é um primeiro passo para a autonomia do estudante, seja como cidadão e/ou como profissional no futuro.

Além disso, o autor aponta que o computador e todas as demais ferramentas articuladas com ele, e em particular a sua linguagem, que no caso os estudantes usaram uma ferramenta mais fácil do que usar diretamente a programação/linguagem em PHP, exige uma apropriação desde os elementos contextuais e técnicos. Paralelamente ainda saberes de outras áreas do conhecimento, por exemplo, no caso do artigo, contextual de que o sistema de inscrição precisa ser de fácil manuseio e acesso, já um técnico seria qualquer um dos elementos apontados pelos estudantes antes desde as utilidades do framework escolhido, e um saber externo seria o que o evento precisa que este sistema registre e gere, como a inscrição com confirmação, listas de chamadas e outras.

Diante de toda reflexão teórica sobre o processo de aprendizagem desses estudantes ao desenvolver o sistema contextualiza-se como cada vez é mais complexo e denso o processo de ensinoaprendizagem (MORIN, 1999) dos estudantes e dos professores que propõem tais práticas, pelo simples fato, de que os saberes trazidos a escola e os interesses são muito diversificados, além de aplicados em muitos cenários. 


\section{METODOLOGIA E AÇÃO}

Este estudo consiste em um relato de caso articulado à experiência. Experiência tal que foi um projeto de ensino idealizado por três professores, um do curso ADS, outro do TPG e outra da Licenciatura em Matemática em dezembro de 2015. Tal evento aconteceu nos dias 5, 6 e 7 de maio de 2016, no IFRS - Campus Osório.

O relato está organizado conforme ocorreu na realidade: primeiro os estudantes apontaram a necessidade de desenvolver um sistema para inscrição; depois procuraram a linguagem para desenvolver e foram adaptando as demandas semanalmente ao sistema, ou seja, os testes do próprio sistema ocorreram paralelamente ao seu desenvolvimento, como um conjunto de acertos e erros, mas o teste final foi colocá-lo em prática. Depois do evento, o grupo que desenvolveu fez os apontamentos do sistema que deveriam ter sido diferentes e o que deu certo. E durante todo esse processo os professores envolvidos com o projeto da semana acadêmica estavam olhando para o processo de aprendizagem desse grupo de estudantes quanto ao desenvolvimento do sistema sempre os questionando sobre suas próprias ações, e é este conjunto que relata-se aqui.

Os estudantes foram convidados a participar voluntariamente, sendo que o curso de Licenciatura em Matemática somente teve ingresso em 2016-1. Conforme explicado na Introdução foram oito estudantes voluntários, e realizava-se encontros semanais à tardinha de 30 minutos, uma vez por semana, para se alinhar as ideias, e trocas online por e-mail e via grupo de Whatsapp ${ }^{\circledR}$ também. Os estudantes se organizaram por equipes para realizar as atividades, e toda a programação e ações foram construídas ora em colaboração ora em cooperação entre professores e estudantes. Além disso, tivemos o apoio de uma tecnóloga do campus. Como dito anteriormente, os estudantes são denominados por A, B, C e D, sendo que os estudantes A e B estão finalizando o curso, ou seja, no último ano, e os demais são técnicos de informática para internet, e estão no primeiro semestre do ADS.

Este artigo se propõe a analisar, em um primeiro momento, partes do processo de aprendizagem dos estudantes do ADS na ação da vivência do desenvolvimento do sistema para a inscrição dos participantes sob o olhar desses estudantes. Assim, os dados analisados são algumas falas dos estudantes e relatos deles nas reuniões e durante o evento, sendo que alguns já foram transcritos na seção anterior e outros são transcritos na próxima seção.

\section{ANÁLISE DE DADOS}

Inicialmente é importante ilustrar ${ }^{7}$ o sistema desenvolvido com as Figuras 1 e 2, obtidas por meio de Print Screen, ou captura de tela, a seguir, realizados pelos estudantes por somente eles terem acesso já que o sistema foi por eles desenvolvidos, e a visualização da programação e dos materiais do evento encontra-se disponível no link: https://inf.osorio.ifrs.edu.br/smadi/informacao.php:

7 Essas figuras servem apenas para ilustrar para que o leitor imagine o que os estudantes produziram e não para fazer um delineamento técnico da área da informática sobre a modelagem do sistema em si. Além disso, apontar o que os estudantes estavam pensando teórica e praticamente em cada situação resolvida por eles próprios ilustradas nestas duas figuras que cada uma apresenta uma situação no caso vivenciada pelos estudantes. 
Figura 1: Página visível ao usuário para fazer a sua inscrição de acordo com a programação.

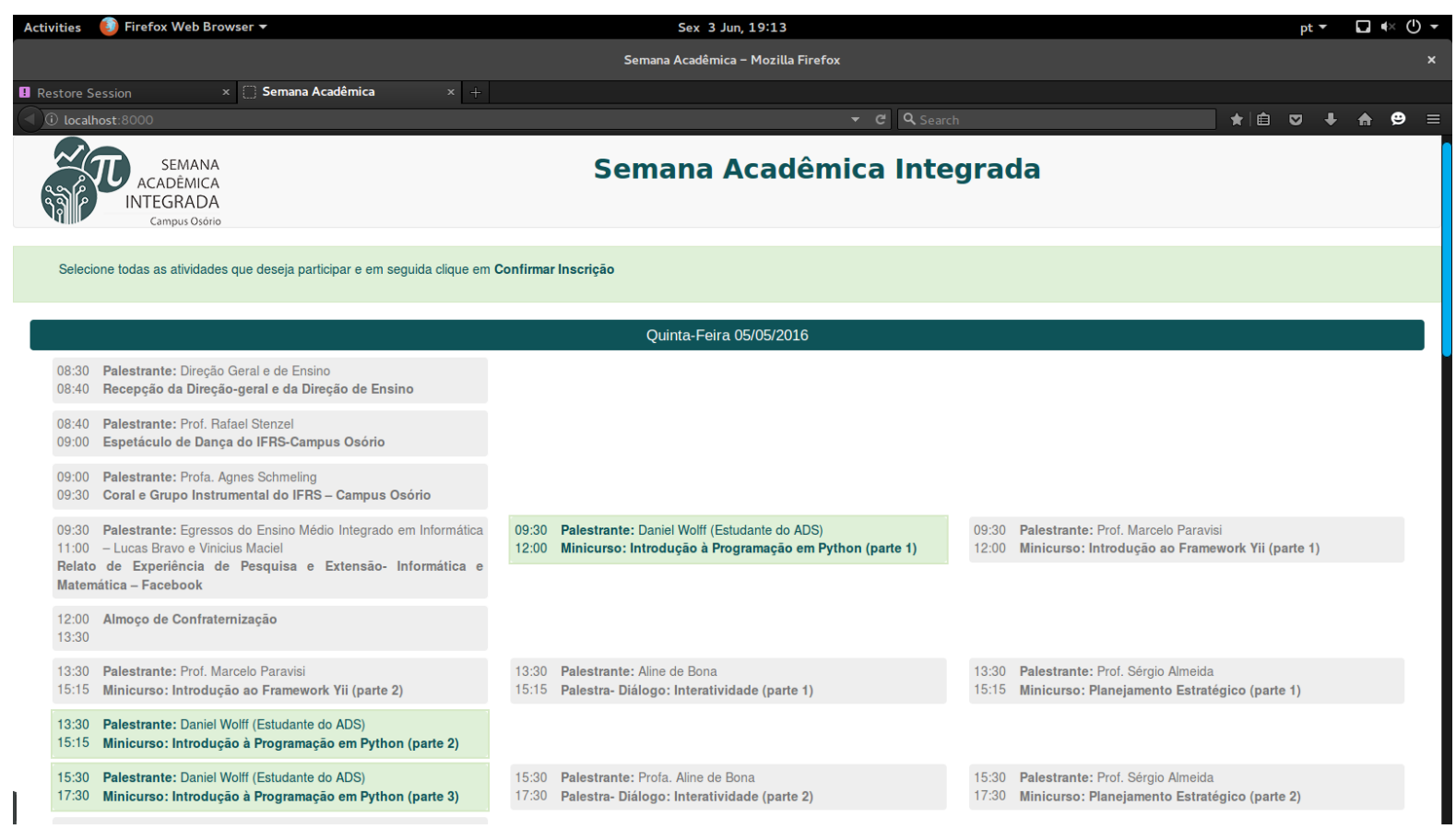

Fonte: Print Screen da Tela do sistema apenas visível aos desenvolvedores.

Como se pode observar, a programação das atividades da semana acadêmica era densa e ocorriam três atividades ao mesmo tempo devido a serem três áreas do conhecimento, sendo esse um fato que muito dificultou o desenvolvimento da programação do sistema, pois o sistema deveria avisar caso o usuário marcasse mais de uma atividade no mesmo horário.

Figura 2: Página que o participante visualiza para fazer a sua inscrição na semana acadêmica.
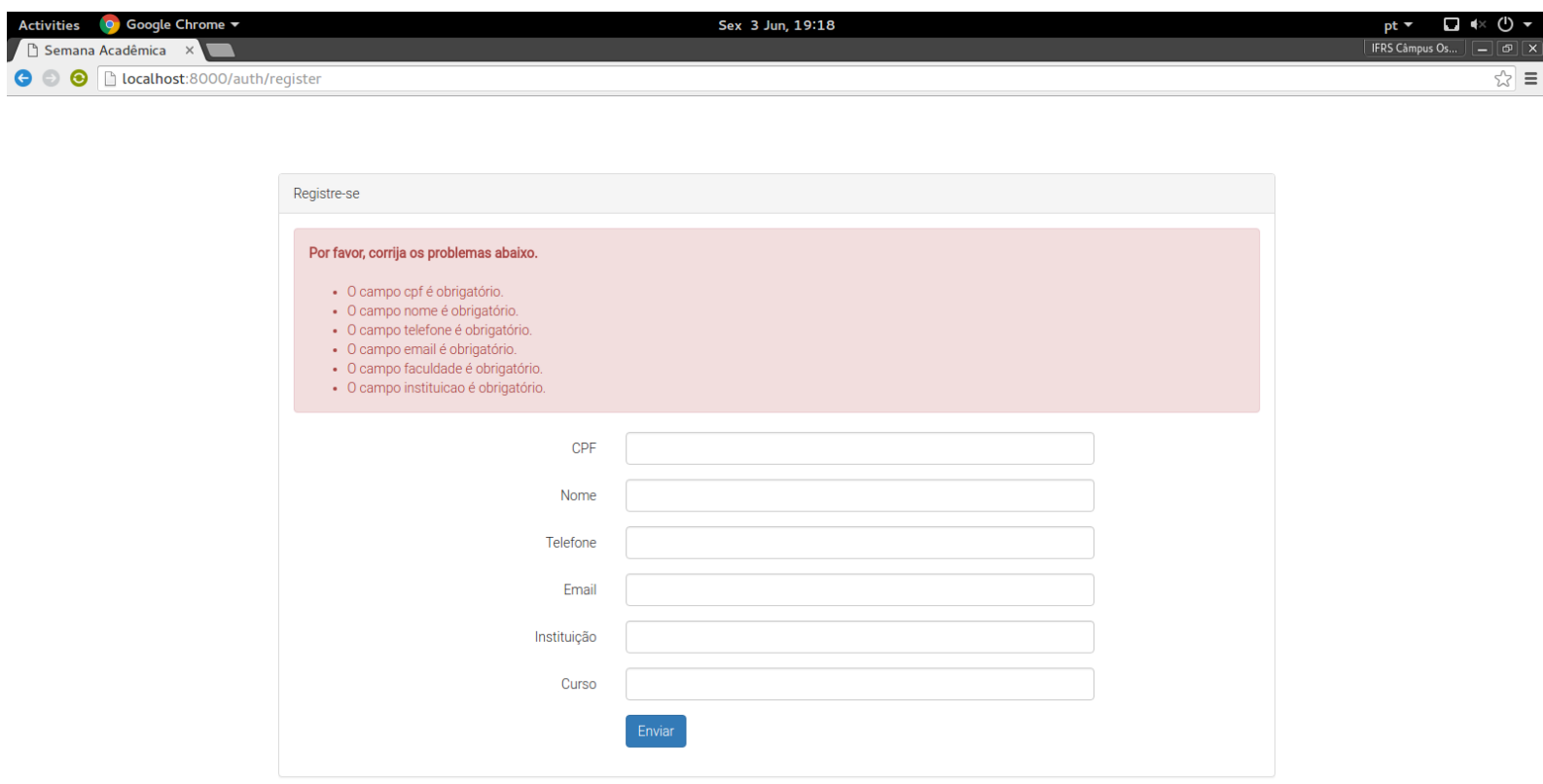

Fonte: Print Screen da Tela do sistema apenas visível aos desenvolvedores.

Os dados apontados acima foram os solicitados pelos professores, pois são esses os dados necessários para a comunicação dos professores com os estudantes, a emissão de certificados e informações necessárias a serem fornecidas aos ministrantes/palestrantes. 
Apresentam-se, a seguir, alguns segmentos das falas dos quatro estudantes ao longo do mês de março e abril, tempo em que ocorreu o desenvolvimento do sistema. Esses segmentos incluem conversas dos estudantes com os professores e entre eles e foram selecionados por apresentar elementos que permitem verificar o processo de aprendizagem dos estudantes quanto a ter a experiência real de desenvolver um sistema para pessoas que não são necessariamente somente da área da informática e com prazo para findar:

Na segunda reunião semanal que ocorreu em março de 2016, na quinta as $18 \mathrm{~h} 30$ 19h:

A: "O sistema está indo, mas eu preciso de ajuda com o banco de dados....estudei e revisei muitas coisas mas falta ainda."

C: "Fiz um rascunho das coisas que precisam ter podemos trocar ideias...ajudo no pouco que sei..."

A: "Esta ótimo, e eu também pedi ajuda para um colega que sabe muito...."

Prof. de Informática: "Quanto a hospedar já falei com o estudante D e ele fará isso, pois foi bolsista do campus e ele sabe fazer...tranquilo"

Analisando o segmento acima, verifica-se que os estudantes colaboram entre si para o desenvolvimento do sistema, trocam ideias e saberes e estão estudando e revisando as disciplinas estudadas para descobrir como solucionar os problemas que surgem. O professor busca um colega e o insere no grupo com alguma atividade específica que ele sabe, e isso é muito significativo, pois divide as tarefas e fortalece o grupo de trabalho. A iniciativa de todos em trocar seus saberes para que seja possível desenvolver um sistema bom é um resultado muito positivo desse tipo de evento para os estudantes de ensino superior, pois é uma ação que terão de fazer em seu espaço de trabalho, já que o trabalho em conjunto resulta em um melhor trabalho do que aquele que se faz sozinho.

Conversas de corredor entre professores:

1) Fim da terceira semana de março de 2016 a à noite:

Prof. de Matemática: "Vai ficar pronto no prazo? Como está? Já estou recebendo emails com pedidos de quando o sistema vai estar no ar."

Prof. de Informática: "Sim, eles estão com algumas dificuldades, pois está dando alguns erros, mas vão conseguir. E tem um estudante B que vai ajudar (...)".

2) Meio da segunda semana de março de 2016 a à tarde:

Prof. da Administração: "As inscrições já estão abertas? Alunos estão perguntando? E eu gostaria de ter a chamada com nomes, e-mails e cursos dos inscritos nas minhas falas (mini-curso e palestras) seria possível?"

Prof. da Matemática: "Sim, claro, falamos na reunião e eles estão desenvolvendo o sistema, logo vão passar para esta fase das chamadas (...) Reforço teu pedido ao prof. de informática e alunos assim que possível".

Observando a primeira conversa, percebe-se que os professores estão envolvidos e comprometidos tanto com os prazos como em cobrar dos estudantes que resolvam as situações do sistema a fim de que o sistema funcione, e na segunda conversa surgem demandas ao sistema que está em desenvolvimento, o que causa uma expectativa da comunidade acadêmica de como será um sistema desenvolvido pelos estudantes do ADS do campus. Tal fato do prazo é uma vivência muito significativa para os estudantes desenvolvedores, já que é uma realidade se trabalhar com prazos, e ainda com demandas que vão surgindo, assim como os problemas. Nesse sentido, a experiência de participar da 
comissão organizadora do evento, em particular da equipe da informática, proporcionou a vivência de lidar com "clientes", ou seja, pessoas que não são da área da informática, mas que sabem o que querem do sistema e não sabem se isso é possível ou não, entre outros elementos.

Conversa dos estudantes com a professora de Matemática no corredor da última semana de março de 2016 a à noite:

Prof. de Matemática: "Como vai? Está quase? Resolveram os problemas?"

Estudante D: "Estamos fazendo, já resolvemos muitos erros, e bugs, mas ainda alguns detalhes como e-mail de confirmação e outros. Temos que buscar dúvidas em fóruns online e ver o que temos para tentar resolver (...)"

Estudante A: "Estou trabalhando online com os estudantes $B$ e $D$, e logo já estará rodando, mas não está sendo fácil, e tem coisas que vejo que talvez outras ferramentas facilitassem ou não sei se não teria outros bugs (...)"

Estudante C: "O banco já está ok, com alguns problemas de compartilhar, mas para chamadas se vê depois (...)".

Ao analisar essa última conversa verifica-se a preocupação dos estudantes em desenvolver corretamente o sistema e em atender toda a demanda, mesmo que por partes, e as ações ora colaborativa e ora cooperativa entre eles, também reflexões e dúvidas se escolheram a melhor ferramenta, no caso o Framework Lavarel, para construir o sistema, mas agora não é possível mudar, mas pensar a outros projetos de desenvolver sistemas como este. Tais ações são parte do processo de aprendizagem dos estudantes e proporcionam a eles autonomia e responsabilidade pelo seu desenvolvimento seja teórico em sala de aula seja prático, e mais uma visão crítica de que as vezes se faz escolhas e mesmo que se perceba não ser a melhor esbarra-se no prazo para poder mudar.

Cabe ainda analisar a transcrição do e-mail da estudante A apresentada no início da seção 2 por dois motivos: primeiro, pela iniciativa da estudante de escolher uma ferramenta e apontar argumentos para usá-la, argumentos que pelos seus colegas estão corretos, e que a teoria aos olhos dos estudantes de informática de um modo geral está alicerçada em fóruns na internet, como ilustrado pelo e-mail do estudante $B$. Um segundo motivo é o apontamento detalhado de cada item técnico que a estudante argumenta, além de outros ela não citou no e-mail talvez por explicar para uma professora que não é da informática, tal fato demonstra comprometimento com seus estudos.

No geral, por meio das falas citadas fica clara a autonomia e responsabilidade dos estudantes quanto ao seu envolvimento com o projeto como uma forma de aprendizagem (FREIRE, 1996). Paralelamente, o processo de trabalho e/ou aprendizagem desses estudantes revelou-se ora colaborativo ora cooperativo - na maioria das vezes - se pensarmos esses conceitos conforme a ótica de Piaget (1973). E a complexidade de se formar um profissional independente de qualquer área do conhecimento requer de todos os envolvidos muitos eventos que possam ser para os estudantes momentos de aplicar a teoria estudada, sendo esse um ponto alto do curso para a formação dos estudantes como profissionais e cidadãos (MORIN, 1999). Lévy (1994) sugere que, na área da informática em particular, é primordial que o estudante não apenas vivencie as questões teóricas e práticas, mas também as relações de trabalho como a problemática de cumprir prazo ao desenvolver um sistema. Isso pode ser apoiado em Papert (1994) uma vez que, segundo o autor, para aprender a aprender é necessário fazer, colocar em prática, tanto sozinho como colaborativa/cooperativamente. Acrescenta-se que o uso das tecnologias digitais potencializa o processo de aprendizagem, em 
particular de reflexão, como se verificou neste estudo com base nas falas da estudante A em suas reflexões e até sugestões ao considerar a possibilidade de usar outra ferramenta.

\section{RESULTADOS E CONSIDERAÇÕES FINAIS}

Primeiramente, o artigo cumpre seu objetivo central de compartilhar a experiência vivida com o projeto de ensino denominado "Semana Acadêmica Integrada" evidenciando um envolvimento dos estudantes de ensino superior de três dos quatro cursos do IFRS - Campus Osório e também dos professores da comissão organizadora.

Além disso, aponta-se como um resultado deste trabalho o desenvolvimento do sistema dentro de um prazo aceitável para o evento ocorrer, ou seja, apenas uns dias de atraso e um sistema que cumpriu suas funcionalidades, mesmo com alguns bugs ou pequenos erros, mas todos plenamente administráveis.

Outro resultado, o mais específico do artigo, refere-se às reflexões da comissão organizadora do evento sobre o desenvolvimento do sistema. Em primeiro lugar, a necessidade de planejar bem com antecedência cada etapa do sistema a fim de minimizar os erros e, em segundo, a necessidade de se pesquisar mais de uma ferramenta para verificar qual a mais adequada à situação. Essa verificação foi submetida a mais de um olhar, ou seja, por alguém de uma linha de programação do tipo PHP e por alguém de outra linha do tipo JAVA.

Por fim, mas não menos importante, destaca-se o rico processo de aprendizagem vivido pelos estudantes que fizeram parte da comissão organizadora. Isso permitiu aos estudantes formandos viver a experiência de como seria uma relação com o cliente - desenvolvedor na prática.

\section{REFERÊNCIAS}

BONA, A.S. De. Espaço de Aprendizagem Digital da Matemática: o aprender a aprender por cooperação. Tese (Doutorado). Programa de Pós-Graduação em Informática na Educação. Porto Alegre: UFRGS, 2012.

BRASIL, Secretaria de Educação Média e Tecnológica. Programa Nacional de Informática Educativa / MEC / SEMTEC. Brasília: PRONINFE, 1994. Disponível em: www.proinfo.mec.gov.br Acesso em 10 / jan / 2016

FREIRE, P.. Pedagogia da Autonomia: saberes necessários a prática educativa. 22ed. São Paulo: Paz e Terra, 1996.

LÉVY, P. As tecnologias da inteligência: o futuro do pensamento na era da informática. Rio de Janeiro: Nova Fronteira, 1994.

MORIN, E. Complexidade e Transdisciplinaridade: a reforma da universidade e do ensino fundamental. Natal: EDUFRN, 1999.

PAPERT, S. A Máquina das crianças. Porto Alegre: Artmed, 1994.

PIAGET, J. Estudos Sociológicos. Rio de Janeiro: Forense, 1973. 